\title{
Genetic diversity study of sorghum (Sorghum bicolor (L.) Moenc) genotypes, Ethiopia
}

\author{
Kassahun TESFAYE \\ Directorate of Crop and Horticulture, Characterization Case Team, \\ Ethiopian Biodiversity Institute \\ e-mail: kasahuntes@gmail.com
}

Manuscript received: March 30, 2017; revised: April 22, 2017; accepted: May 15, 2017

\begin{abstract}
Sorghum bicolor is one of the most important cereal crops around the world, particularly in Africa, highly cultivated for dietary staple. For this reason, a good knowledge and usage of this genetic resource in sorghum accessions is highly vital for improving crop quality. Analysis of genetic variability among the accessions will enable accurate results in breeding. The research design used was augmented design, which is common in many gene banks. This research finding would be used later by plant breeders to select best performers for further evaluation of the crop and obtain a new variety of sorghum.
\end{abstract}

Keywords: genetic diversity, genetic variability

\section{Introduction}

Sorghum is ranked the fifth most produced food crop in the world, and it is a dietary staple for over half a billion people in over thirty countries, most of them being developing countries [1], [2]. It is also the second most cultivated cereal crop in Africa, where cultivation of farmer's variety of sorghum is the predominant form of agriculture next to maize [3]. Sorghum was domesticated in the African continent, particularly in East Africa, Ethiopia, from where it was believed to be introduced to other regions of the world with a wide agro-ecology [4]. It is one of most vital crops cultivated over a wide extreme ecological habitat in Ethiopia, in the range of low to high altitude (400-3,000 meters above sea level) [5]. It is well adapted to the range of environmental conditions in semi-arid Africa, with high variability [1], [6], [7]. Sorghum is the single most important cereal in the lowland areas because of its extreme resistance to water stress [8]. 
Sorghum bicolor contains both cultivated and wild relative races, and it provides a substantial amount of genetic diversity for traits of agronomic importance so as to develop the crop's different variety of interest for plant breeders [9].

Ethiopia is known to be one of the Vavilovian centres of origin, or diversity for many cultivated and wild species of crops, including sorghum [10], [11]. Sorghum is one of the cereal crops for which Ethiopia has been credited as being a centre of origin and/or diversity [10], [12]. In the high altitude areas, the landrace sorghum germplasm has often been the only well-adapted material that is easily accessible for use. There is a higher probability of genetic material exchange to occur between the wild (Sorghum bicolor subsp. arundinaceum) and the cultivated sorghum since both types mostly grow in sympathy with the wild and weedy relatives in most sorghum-growing parts of Ethiopia, mainly in the south-eastern and south-western part of the country [1]. A greater extent of genetic diversity existed within a species, often used as a measure of its ability to adapt to its new environment. Hence, biodiversity is like a wealth for coping with environmental fluctuations. Sorghum has one of the largest crop germplasm collections, consisting of more than 42,000 accessions worldwide [13], [14]. The largest diversity of the crop germplasm provides greater opportunities for improvement regarding its environmental adaptability and acquiring better agronomic traits from the crop species. Identifying and selecting the best varieties meeting specific local food and industrial requirements from this great biodiversity is of high importance for the food security assurance of any given country [14].

Having a good knowledge of the genetic diversity of a crop often enables the plant geneticist to select the desirable family for the breeding programme and gene introgression from distantly related germplasm. The more variable genotypes or accessions can be crossed to produce better varieties that can tolerate a range of environmental changes to abiotic and biotic stresses. Therefore, a better understanding of the genetic diversity in sorghum crop species will definitely facilitate the further improvement of this cereal crop concerning its genetic architecture [15].

Genetic diversity in the crop species is one of the precious gifts of nature to us, and it arises due to geographical isolation or genetic boundary to gene flow. Phenotypic traits are conventional tools to analyse the genetic diversity since studies of this type generally do not require complicated equipment and methodology. They are very simple and easy to score. These simple observable morphological characters are the useful tools for primary genetic diversity study as they provide a quick and useful approach for assessing the range of diversity in the crop species. Over the years, a number of studies have dealt with estimating genetic diversity in cultivated sorghum using morphological traits [16-22].

The use of phenotypic characters is the most advisable method most often used to estimate relationships between genotypes. The genetic variability of 
cultivated crops and their wild relatives together form a potential and continued source for breeding new and better crop varieties. A better understanding of the genetic diversity in sorghum would greatly contribute to crop improvement with a view to food quality and other important agronomic traits. Therefore, there is a need to evaluate the available accessions for genetic diversity and identify the best accessions according to their performance.

There are around 11,353 sorghum accessions collected and conserved in Ethiopian Biodiversity Institute gene bank, of which 8,913 accessions were characterized by plant breeders and other researchers, and further 2,440 sorghum accessions are yet to be screened for their potentially useful characters. For this reason, the main objective of this research was to determine the range of variation among sorghum accessions in general and to classify them into clusters based on their similarity features regarding the traits under study (quantitative characters) and also to generate data on their performance for plant breeders for further evaluation of the crop in particular.

\section{Materials and methods}

The study on sorghum was conducted in Oromia Regional State, Arsi Zone, Arsi Negale Research sub-centre in the summer of 2014/15, during the main cropping season. This region is located in the Western Oromia Regional State, with an altitude of 1,960 meters above sea level and $7^{\circ} 20^{\prime} \mathrm{N}$ latitude and $38^{\circ} 09^{\prime} \mathrm{E}$ longitude. 117 Sorghum accessions and two standard checks (Geremew and Baji), which were obtained from Melkasa Agricultural Research Centre (MARC), were used for yield and drought resistance traits comparison for the research, respectively. The research design used was augmented design with no replication among the sorghum accessions, except for the two standard checks replicated in every block due to insufficient seed availability. The sorghum genotypes were planted in two rows with a spacing of $75 \mathrm{~cm} \times 30 \mathrm{~cm}$ between and within rows respectively, with a row length of $5 \mathrm{~m}$. DAP, Urea, and other management practices were applied as per recommended for the site.

Morphological data was recorded with the help of the International Plant Genetic Resources Institute (IPGRI), nowadays known as "Bioversity International", based in Italy, Rome. The characterization descriptor list for sorghum (E and F, 1993) was used by randomly selecting and tagging 20 individual plants for diversity study research from each accession. For each selected plant, the quantitative trait to be studied in the accession was coded as Basal tiller (BT), Nodal tiller (NT), Leaf number at maturity (LN), Plant height $(\mathrm{PH})$ in $\mathrm{cm}$, Panicle length (PL) in $\mathrm{cm}$, Panicle width (PW) in $\mathrm{cm}$, thousand grain weight (GY) in gm, Days to $50 \%$ flowering (DF), and Days to $50 \%$ maturity (DM). The collected data were calculated by statistical analysis of 
variance using MINITAB (version 13.0) and SAS (9.2). Variances and coefficient variation were calculated as per formula, as it was suggested [23].

Table 1. List of the sorghum accessions and the two standard checks used for the study, obtained from the Ethiopian Biodiversity Institute

\begin{tabular}{|c|c|c|c|c|c|c|c|c|c|}
\hline No & $\begin{array}{c}\text { Acc. } \\
\text { Number }\end{array}$ & No & $\begin{array}{c}\text { Acc. } \\
\text { Number }\end{array}$ & No & $\begin{array}{c}\text { Acc. } \\
\text { Number }\end{array}$ & No & $\begin{array}{c}\text { Acc. } \\
\text { Number }\end{array}$ & No & Acc. Number \\
\hline 1 & 9125 & 28 & 219976 & 55 & 233816 & 82 & 237778 & 109 & 241689 \\
\hline 2 & 9161 & 29 & 219982 & 56 & 233819 & 83 & 237784 & 110 & 241690 \\
\hline 3 & 9630 & 30 & 223513 & 57 & 233820 & 84 & 238379 & 111 & 241692 \\
\hline 4 & 15817 & 31 & 223533 & 58 & 233821 & 85 & 238382 & 112 & 242029 \\
\hline 5 & 15821 & 32 & 223581 & 59 & 233822 & 86 & 238384 & 113 & 242030 \\
\hline 6 & 70940 & 33 & 226053 & 60 & 233830 & 87 & 238385 & 114 & 242034 \\
\hline 7 & 71806 & 34 & 227098 & 61 & 233832 & 88 & 238387 & 115 & 242035 \\
\hline 8 & 71889 & 35 & 227202 & 62 & 233835 & 89 & 238388 & 116 & 242038 \\
\hline 9 & 73657 & 36 & 227203 & 63 & 233836 & 90 & 238392 & 117 & 69057 \\
\hline 10 & 74788 & 37 & 227205 & 64 & 233837 & 91 & 238407 & 118 & Germew (ck 1) \\
\hline 11 & 73957 & 38 & 227206 & 65 & 234056 & 92 & 238410 & 119 & Baji (ck2) \\
\hline 12 & 200117 & 39 & 227208 & 66 & 234057 & 93 & 238438 & & \\
\hline 13 & 200646 & 40 & 227213 & 67 & 234067 & 94 & 238453 & & \\
\hline 14 & 200774 & 41 & 228091 & 68 & 234081 & 95 & 241197 & & \\
\hline 15 & 201444 & 42 & 228111 & 69 & 235468 & 96 & 241199 & & \\
\hline 16 & 201768 & 43 & 228544 & 70 & 235476 & 97 & 241218 & & \\
\hline 17 & 201817 & 44 & 228548 & 71 & 235597 & 98 & 241221 & & \\
\hline 18 & 201923 & 45 & 228741 & 72 & 235615 & 99 & 241235 & & \\
\hline 19 & 201936 & 46 & 228743 & 73 & 235624 & 100 & 241237 & & \\
\hline 20 & 201956 & 47 & 231201 & 74 & 235626 & 101 & 241240 & & \\
\hline 21 & 206944 & 48 & 233686 & 75 & 236728 & 102 & 241245 & & \\
\hline 22 & 206950 & 49 & 233689 & 76 & 237033 & 103 & 241246 & & \\
\hline 23 & 216827 & 50 & 233693 & 77 & 237037 & 104 & 241247 & & \\
\hline 24 & 217694 & 51 & 23699 & 78 & 237278 & 105 & 241248 & & \\
\hline 25 & 217697 & 52 & 233700 & 79 & 237281 & 106 & 241251 & & \\
\hline 26 & 217698 & 53 & 23707 & 80 & 237769 & 107 & 241273 & & \\
\hline 27 & 219974 & 54 & 233808 & 81 & 237771 & 108 & 241275 & & \\
\hline
\end{tabular}




\section{Results and discussions}

\subsection{Analysis of variance}

The analysis of variances (ANOVA) table revealed that there is diversity among the accessions of sorghum for all characters studied; in other words, there were significant differences $(\mathrm{p}<0.05)$, as it was indicated in Table 2 .

Table 2. The mean square of the tested sorghum accessions for the nine quantitative characters

\begin{tabular}{|c|c|c|c|c|c|c|c|c|c|c|}
\hline \multirow{2}{*}{$\begin{array}{l}\text { Source of } \\
\text { variation }\end{array}$} & \multirow{2}{*}{$\begin{array}{l}\text { Degree of } \\
\text { freedom }\end{array}$} & \multicolumn{9}{|c|}{ Mean squares } \\
\hline & & BT & NT & $\mathrm{LN}$ & $\mathrm{PH}$ & PL & PW & GY & DF & $\mathrm{DM}$ \\
\hline $\begin{array}{l}\text { Between } \\
\text { Groups }\end{array}$ & 7 & 0.674 & 1.462 & 30.27 & 5.14 & 130.76 & 9.29 & 110.30 & 157.41 & 200.36 \\
\hline $\begin{array}{l}\text { Within } \\
\text { Groups }\end{array}$ & 111 & 0.25 & 0.773 & 4.19 & 3.41 & 42.42 & 4.53 & 98.36 & 33.48 & 64.44 \\
\hline Mean & & 0.26 & 0.77 & 9.21 & 2.67 & 24.69 & 6.88 & 23.41 & 102.7 & 71.06 \\
\hline SE & & 0.48 & 0.08 & 0.22 & 0.17 & 0.63 & 0.20 & 0.56 & 0.99 & 0.78 \\
\hline
\end{tabular}

\subsection{Mean and range values}

The mean values of the genotypes indicated that there are some genotypes performing better than the two standard checks, "Geremew and Baji", for some of the traits studied. Only one genotype matured earlier than the two standard checks, which was ACC No 238453 (51 days), while some others matured at the same time as the two standard checks, e.g. ACC No 9161 (54 days) and ACC no 9630 (54 days), ACC No 237769 (59 days), ACC No 234056 (59 days), and ACC No 241275 (59 days), whereas the two checks matured after 54 days (Geremew) and 59 days (Baji) respectively.

Generally, a considerable mean range value was observed for all the traits (Fig. 1). Mean ranges of 0 to $2.5,0$ to $3.1,4.75$ to $14.66,1.45$ to $4,11.34$ to 45.6 , 4.3 to $10.3,12$ to $36.4,79$ to 131 , and 51 to 88 were recorded for BT, NT, LN, PH, PL, PW, GY, DF, and DM, respectively, which clearly shows genetic diversity in the sorghum accession for the studied traits. 


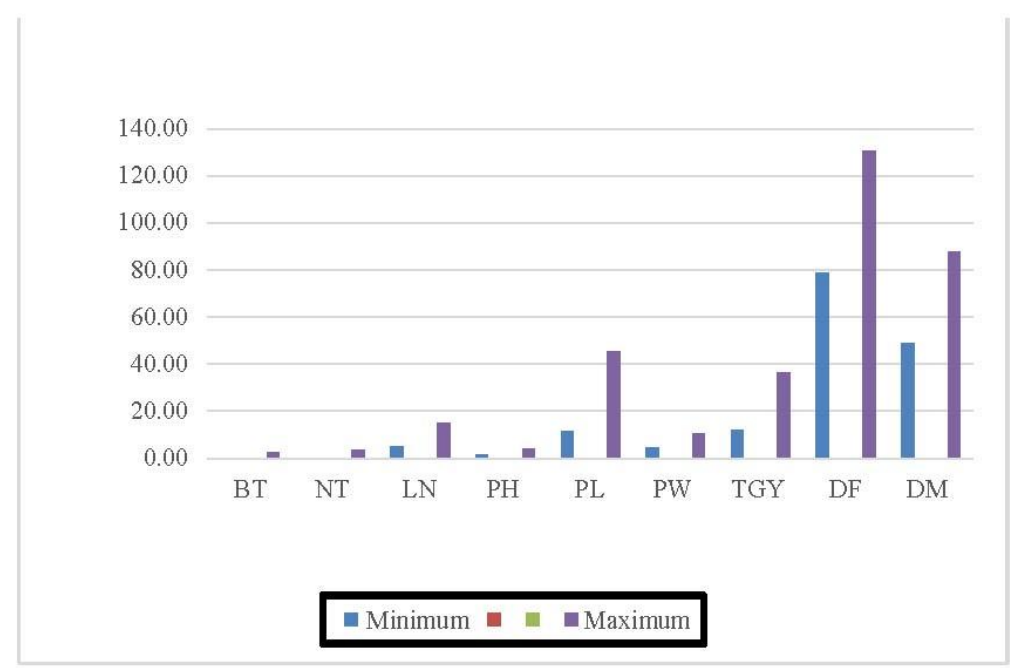

Figure 1. Minimum and maximum values of nine quantitative traits of 119 Sorghum genotypes

\subsection{Phenotypic and genotypic coefficients of variation}

Low PCV and GCV values were calculated for the traits considered according to [23]. This showed that there is no wide variation among genotypes for the traits considered, except for thousand grain yields (GY) and panicle length (PL), as it was illustrated in the bar graph (Fig. 2).

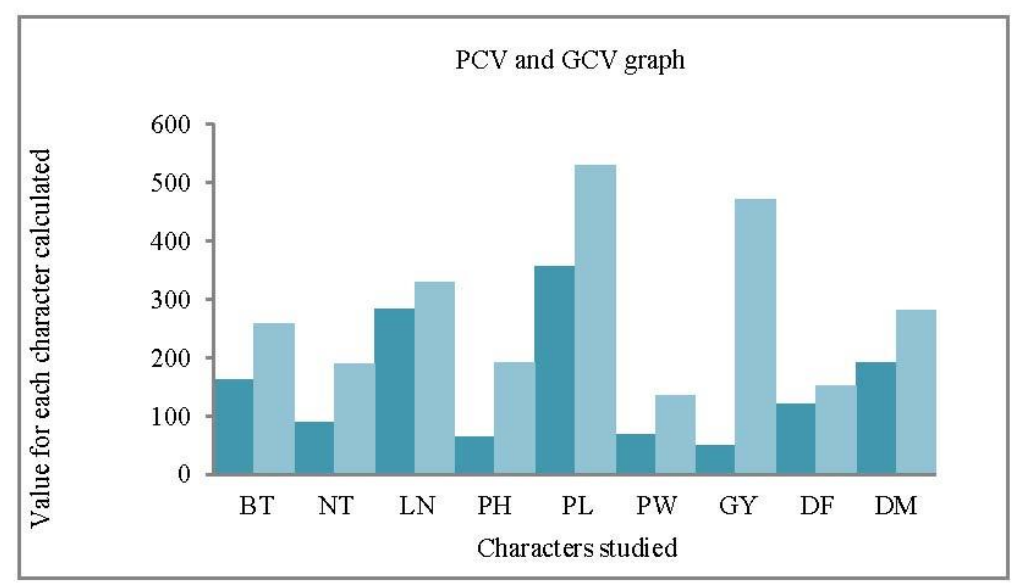

Figure 2. Phenotypic and genotypic coefficient of variation of all characters considered 


\subsection{Principal component analysis}

Principal component analysis was performed in order to reduce a large set of phenotypic traits to a more meaningful smaller set of traits and to know which trait is contributing to maximum variability, because genetic improvement depends on the magnitude of genetic variation. The first four principal components (PCs), with eigenvalues greater than 1, explained about $71.9 \%$ of the total variation among accessions for all traits, as it was given in Table 4. The first principal component (PC1) obtained was $26.9 \%$ of total variance and had high contributing factor loading from $\mathrm{LN}$ and $\mathrm{PH}$, which were the most important contributing traits for the relative magnitudes of eigenvectors for the first principal component, while the second principal component (PC2) had high contributing factor loading from PL, GY, and DF, which was $18.9 \%$; thirdly, it had a high contributing factor loading from BT and NT for the third principal component (14.6\%), and, finally, it had a high contributing factor loading from $\mathrm{PW}$ and $\mathrm{DM}$ for the fourth principal component (11.6\%).

Table 3. Eigenvectors and eigenvalues of the nine principal components of the 119 sorghum accessions

\begin{tabular}{|cccccccccc}
\hline Traits & \multicolumn{7}{c}{ Eigenvectors } \\
\cline { 2 - 11 } & PC1 & PC2 & PC3 & PC4 & PC5 & PC6 & PC7 & PC8 & PC9 \\
BT & 0.214 & 0.416 & -0.491 & -0.134 & -0.297 & -0.139 & 0.199 & -0.610 & -0.042 \\
NT & -0.041 & 0.405 & -0.630 & 0.036 & 0.172 & 0.140 & -0.078 & 0.614 & 0.064 \\
LN & -0.589 & 0.147 & 0.010 & 0.181 & 0.080 & 0.007 & 0.045 & -0.231 & 0.773 \\
PH & -0.527 & 0.016 & -0.123 & 0.398 & 0.252 & 0.099 & 0.206 & -0.197 & -0.627 \\
PL & 0.244 & -0.504 & -0.277 & 0.270 & 0.005 & 0.083 & 0.688 & 0.093 & 0.220 \\
PW & -0.0372 & -0.156 & -0.101 & -0.458 & -0.056 & -0.708 & 0.241 & 0.218 & -0.086 \\
GY & -0.026 & 0.490 & 0.446 & -0.273 & -0.018 & 0.285 & 0.611 & 0.171 & -0.042 \\
DF & -0.033 & -0.177 & -0.092 & -0.044 & 0.829 & 0.356 & -0.063 & 0.154 & -0.080 \\
DM & 0.136 & 0.303 & 0.229 & 0.656 & 0.349 & -0.485 & 0.042 & 0.221 & -0.007 \\
\hline Eigenvalue & 2.4174 & 1.6985 & 1.3098 & 1.0468 & 0.8261 & 0.6778 & 0.4942 & 0.4133 & 0.1161 \\
\hline \% of total variance explained & 0.269 & 0.189 & 0.146 & 0.116 & 0.092 & 0.075 & 0.055 & 0.046 & 0.013 \\
\% cumulative variance & & & & & & & & & \\
explained & 0.269 & 0.457 & 0.603 & 0.719 & 0.811 & 0.886 & 0.941 & 0.987 & 1.000 \\
\hline
\end{tabular}

The score plot of 119 accessions based on the first two principal components is presented in Figure 3. Accessions (arranged by their plot number) were distributed in different groups, which clearly showed genetic diversity among sorghum accessions. 


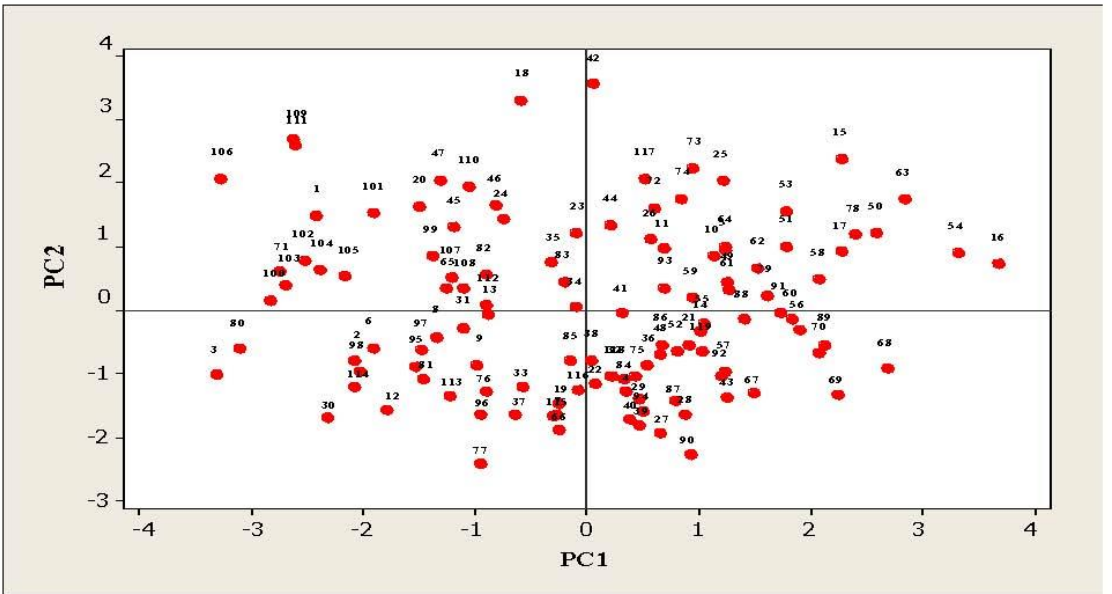

Figure 3. Distribution of sorghum accessions for the first two principal components (PC1 and PC2) based on nine quantitative traits given in their order of arrangement

\subsection{Phenotypic and genotypic variation}

Low phenotypic and genotypic values were calculated for the traits considered, as it was explained in Figure 4 [23]. This indicated that there is no wide variation among genotypes for the traits studied, except for TGY, PL, and DM, which showed variability among the sorghum accessions for the traits considered.

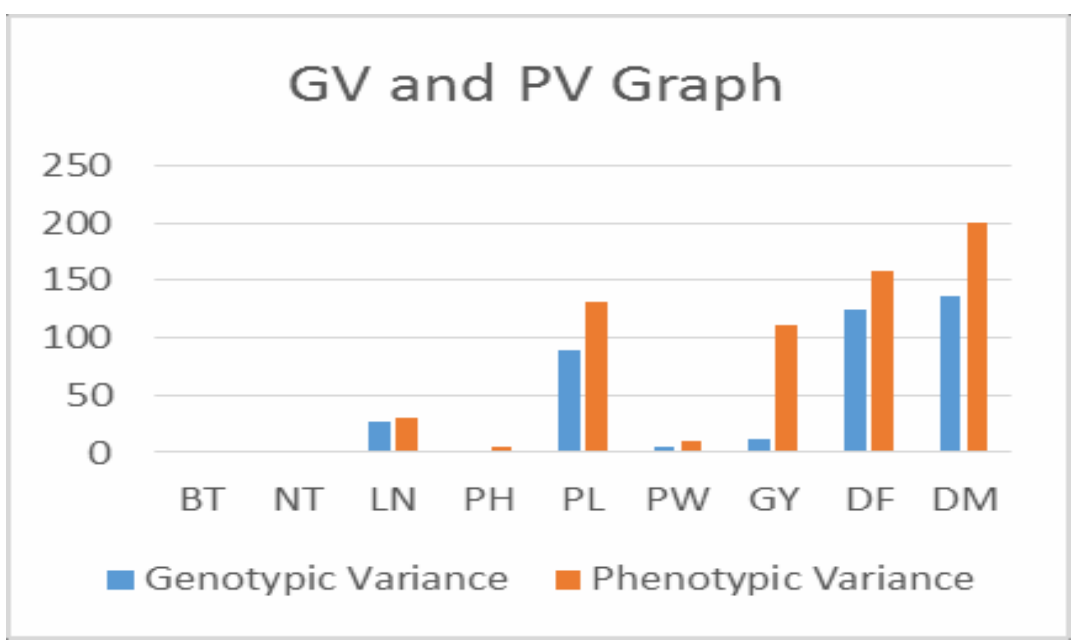

Figure 4. Genotypic and phenotypic variation bar graph of sorghum accessions considered for the nine quantitative traits 


\subsection{Cluster analysis}

Cluster analysis was performed on the Euclidean distance matrix utilizing Ward's linkage method, and the resulting dendrogram is given in Figure 5, using MINITAB software version 14 . The 117 sorghum accessions along with the two standard checks formed 13 clusters at a $40.88 \%$ similarity level. The result of the hierarchical cluster analysis indicated that 119 sorghum accessions were grouped into thirteen different clusters with a range of accessions that are categorized because of their similar performance for the trait under study (i.e. 5, 51, 4, 15, 8, $9,13,7$, and 3 accessions per cluster respectively) from cluster number 1 up to 9 , while the rest of the cluster numbers, $10,11,12$, and 13 , have only one accession per cluster. The clustering pattern indicated the existence of a significant amount of variability among the sorghum species. The two standard checks used were grouped into cluster 8 along with five other sorghum genotypes that performed in a similar way for the studied quantitative characters. Cluster 7 and 12 have the largest distance between them (56), while cluster 3 and cluster 5 have the smallest distance (13.5).

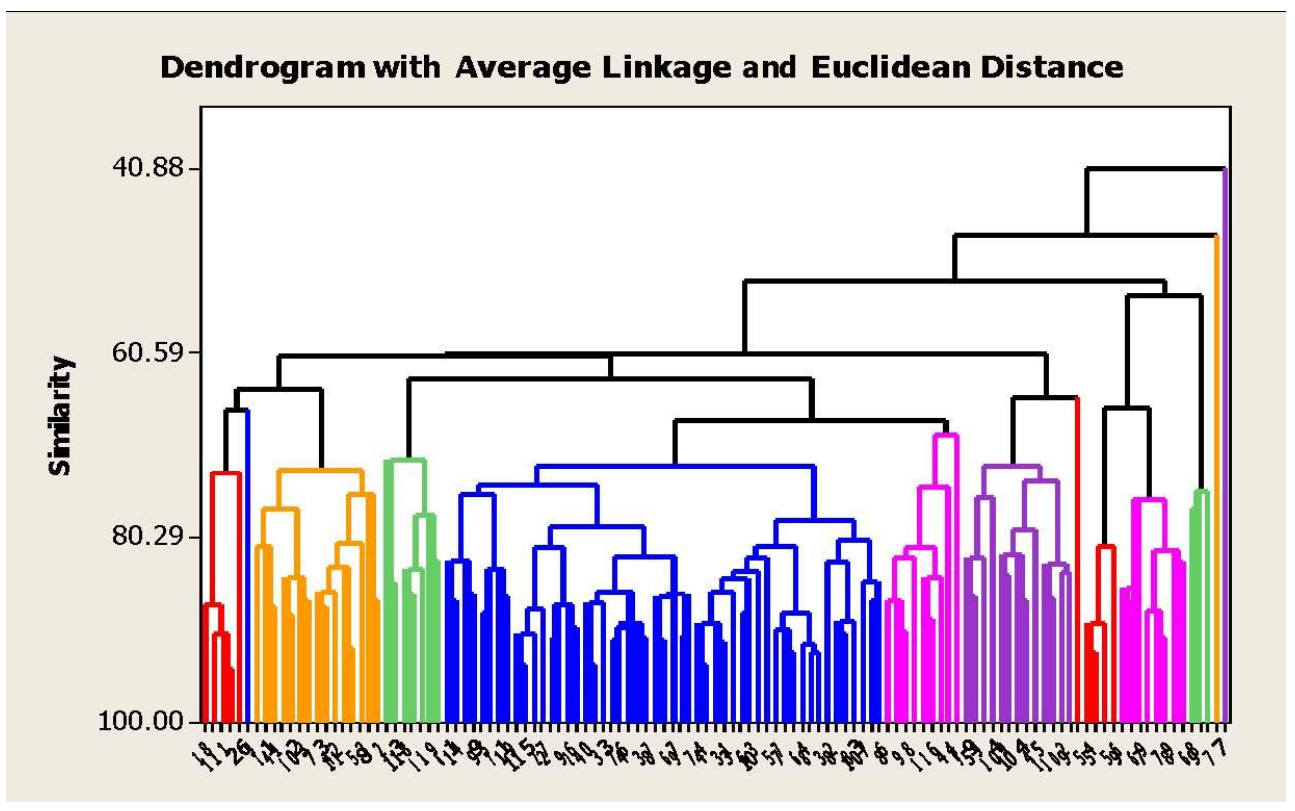

Figure 5. Cluster analysis of 119 sorghum genotypes 


\section{Conclusions}

The diversity study of sorghum clearly indicates a diversity among the accessions. Landraces on a farm are acknowledged as the main source of genetic diversity for gene banks and breeding programmes, yet many studies have shown that genetic erosion is occurring on farmer varieties because of the utilization of high-yielding varieties. It has also been suggested, however, that only landraces which are not used for specific reasons are subjected to genetic erosion, while those which are (and have been for years) selected by farmers for certain desirable traits are likely to survive on a farm alongside improved varieties.

Based on all the parameters used to see if there was diversity among the sorghum accessions, the tested genotypes showed genetic variability for the traits considered. 119 genotypes are grouped into 13 cluster groups, which consists of 51 genotypes for the largest cluster and a single accession for four cluster groups (clusters 10,11, 12, and 13), having different values of squared distance for each cluster group ranging from 13.5 to 56 , which clearly shows that there exists a diversity of the sorghum genotypes.

\section{Acknowledgements}

The author of the research would like to thank the Ethiopian Biodiversity Institute for their financial support to conduct this study.

\section{References}

[1] Doggett, H. (1988), Sorghum. Tropical Agriculture Series. $2^{\text {nd }}$ ed. CTA, Wageningen, The Netherlands.

[2] Rohrbach, D. D., Mtenga, K., Kiriwaggulu, J. A. B., Monyo, E. S., Mwaisela, F., Saadan, H. M. (2002), Comparative study of three community seed supply strategies in Tanzania. International Crops Research Institute for the Semi-Arid Tropics, Bulawayo, Zimbabwe.

[3] Gerda, M. B., Christopher, D. V. (2007), Can GM sorghum impact Africa? Trends in Biotechnology 26(2), 64-69.

[4] Li, R., Zhang, H., Zhou, X. et al. (2010), Genetic diversity in Chinese sorghum landraces revealed by chloroplast simple sequence repeats. Genetic Resources and Crop Evolution $57(1), 1-15$.

[5] Teshome, A., Patterson, D., Asfaw, Torrance, J. K., Arnason, J. T. (2007), Changes of Sorghum bicolor landrace diversity and farmers' selection criteria over space and time, Ethiopia. Genet.Resour. Crop Evol. 54, 1219-1233.

[6] Teshome, A., Baum, B. R., Fahrig, L., Torrance, J. K., Arnason, T. J., Lambert, J. D. (1997), Sorghum [Sorghum bicolor (L.) Moench] landrace variation and classification in North Shewa and South Welo, Ethiopia. Euphytica 97, 255-263.

[7] Rami, J. F., Dufour, P., Trouche, G., Fliedel, G., Mestres, C., Davries, F., Blanchard, P., Hamon, P. (1998), Quantitative trait loci for grain quality, productivity, morphological and agronomical traits in sorghum (Sorghum bicolar L. Moench). Theories of Applied Genetics 97, 605-616. 
[8] Kebede, Y. (1991), The role of Ethiopian sorghum germplasm resources in the national breeding programme. In: J. M. M. Engels, J. G. Hawkes, M. Worede (eds.), Plant Genetic Resources of Ethiopia. Cambridge University Press, Cambridge. 315-322.

[9] Hart, G., Schertz, K., Peng, Y., Syed, N. (2001), Genetic mapping of Sorghum bicolor (L.) Moench QTLs that control variation in tillering and other morphological character. Theoretical and Applied Genetics 103, 1232-1242. http://dx.doi.org/10.1007/s001220100582.

[10] Vavilov, N. I. (1951), The origin, variation, immunity and breeding of cultivated plants. Chron. Bot. 13: 1-366.

[11] Harlan, J. R. (1971), Agricultural origins: Centres and non centres. Science 174, 468-473.

[12] Harlan, J. R. (1992), Crops and Man. $2^{\text {nd }}$ Edition, Am. Soc. Agron. and Crop Soc. Am., Madison, WI.

[13] Huang, Y. (2004), Evaluation of genetic diversity in sorghum germplasm using molecular markers. International Plant \& Animal Genome XII Conference, San Diego, CA, Poster 265. p.138.

[14] Dahlberg, J. A., Zhag, X., Hart, G. E., Mullet, J. E. (2002), Comparative assessment of variation among sorghum germplasm accessions using seed morphology and RAPD measurements. Crop Science Journal 42(1), 291-296.

[15] Jayarama Chandran, M., Kumaravadivel, N., Kandasamy, G., Eapen, S. (2011), Comparison of genetic variability induced by radiation and tissue culture in sorghum. International Journal of Bio-Resource and Stress Management 2(3), 329-333.

[16] Zongo, J.-D., Gouyon, P. H., Sandmeier, M. (1993), Genetic variability among sorghum accessions from the Sahelian agro ecological region of Burkina Faso. Biodiversity and Conservation 2(6), 627-636.

[17] Appa, R. S., Rao, P., Mengesha, M. H., Reddy, V. G. (1996), Morphological diversity in sorghum germplasm from India. Genetic Resources and Crop Evolution 43(6), 559-567.

[18] Ayana, A., Bekele, E. (1998), Geographical patterns of morphological variation in sorghum (Sorghum bicolor (L.) Moench) germplasm from Ethiopia and Eritrea: qualitative characters. Hereditas 129(3), 195-205.

[19] Kumar, L. S. (1999), DNA markers in plant improvement: an overview. Biotechnology Advances 17(2-3), 143-182.

[20] Dahlberg, J. A., Zhang, X. Hart, G. E., Mullet, J. E. (2002), Comparative assessment of variation among sorghum germplasm accessions using seed morphology and RAPD measurements. Crop Science 42(1), 291-296.

[21] Shehzad, T., Okuizumi, H., Kawase, M., Okuno, K. (2009), Development of SSR-based sorghum (Sorghum bicolour (L.) Moench) diversity research set of germplasm and its evaluation by morphological traits. Genetic Resources and Crop Evolution 56(6), 809-827.

[22] Adugna, A. (2014), Analysis of in situ diversity and population structure in Ethiopian cultivated (Sorghum bicolour (L.) Moench) landraces using phenotypic traits and SSR markers. Springer Plus 3(1), 1-14.

[23] Falconer, D. S., Mackay, T. F. C. (1996), Introduction to quantitative genetics. $4^{\text {th }}$ ed. Prentice Hall, Harlo, UK. 